\title{
Austausch auf europäischer Ebene
}

\begin{abstract}
EU-Bürgerdialog mit Günther Oettinger und Malu Dreyer Im Fokus des EU-Bürgerdialogs im Kurfürstlichen Schloss Mainz standen Fragen wie die Zukunft der EU beziehungsweise wie es mit Europa weitergeht, aktuelle Herausforderungen und deren Vermittlung an die Menschen. Dazu luden die RheinlandPfälzische Landesregierung und die EU-Kommission alle Bürger ein. Ministerpräsidentin und aktuelle Bundesratspräsidentin Malu Dreyer und EU-Haushaltskommissar Günther Oettinger stellten sich allen Fragen und Meinungen aus dem Auditorium. Hierzu zählten beispielsweise Fragen zur Flüchtlingskrise, der Gedanke Europas, die europäische Währung, die mögliche Erweiterung der EU, die Finanzierbarkeit bis hin zu speziellen Fragen der Bereiche Wirtschaft und Subventionierung sowie Menschenrechte. Schüler eines Gymnasiums vermittelten die Sorgen der nachwachsenden Generation in einem künftigen Europa.
\end{abstract}

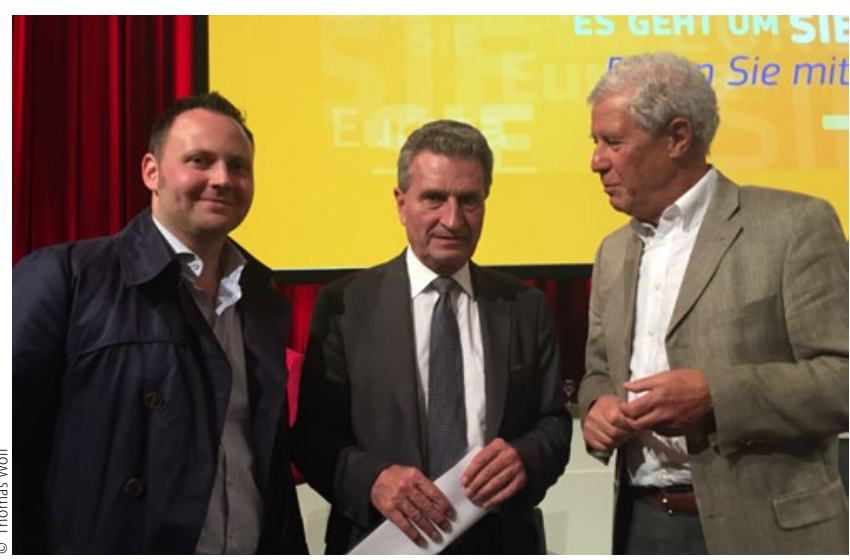

Sprachen über Herausforderungen Europas und Standpunkte des FVDZ: Priv.-Doz. Dr. Thomas Wolf, EU-Haushaltskommissar Günther Oettinger und Dr. Ernst-J. Otterbach (v.l.)

Dr. Ernst-Jürgen Otterbach und Priv.-Doz. Dr. Thomas Wolf, die den Bundesvorstand des Freien Verbands Deutscher Zahnärzte (FVDZ) europa- und außenpolitisch international vertreten, nutzten die Gelegenheit, dem EU-Kommissar Oettinger einige Standpunkte des Verbandes in einem persönlichen Gespräch zu vermitteln. Außerdem überreichten sie ihm eine schriftliche Stellungnahme zum aktuellen EU-Dienstleistungspaket. Oettinger sicherte Unterstützung zu und forderte den FVDZ auf, sich auf Kommissions- und Parlamentsebene lautstark weiter zu artikulieren und sich mit diesem Anliegen unbedingt Gehör zu verschaffen.

\section{Europäisches Studentenparlament in Cardiff}

$\mathrm{Zu}$ einem internationalen Austausch trafen sich im April die Vertreter der nationalen Studierenden-Vertretungen Europas im walisischen Cardiff. Neben Workshops zu Fachthemen und der Industrie standen auch standespolitische Themen auf der Agenda: zum Beispiel Ausbildung, berufliche Spezialisierung, Rahmenbedingungen für eine Facharzt-Ausbildung in der EU,

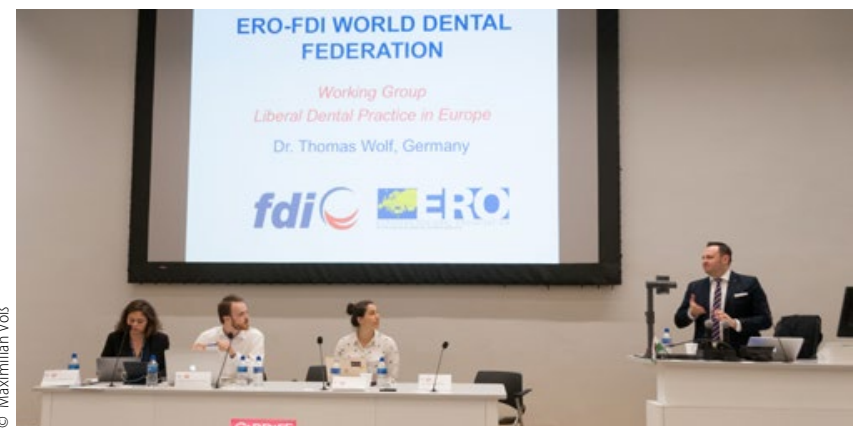

Erst die Arbeit,...

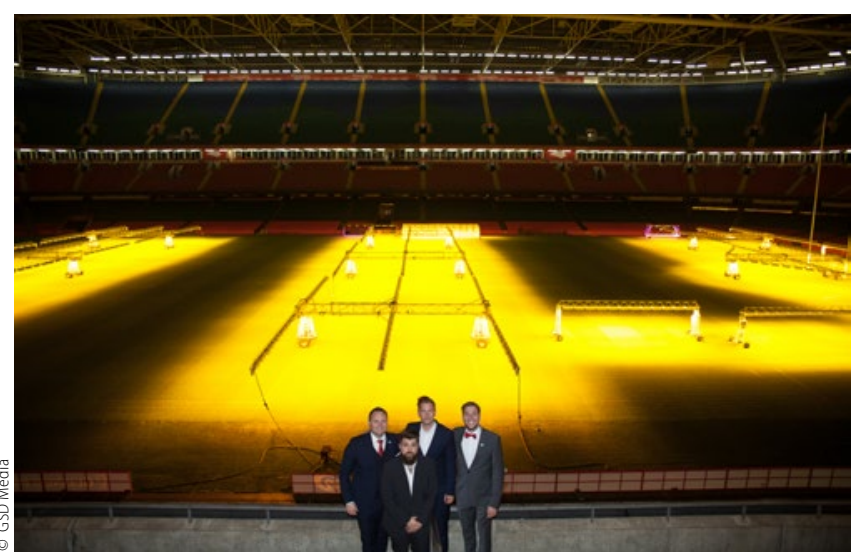

...dann das Vergnügen. Im Stadion von Cardiff: PD Dr. Thomas Wolf, Pascal Siena, Felix Roth und Maximilian Voß (v.l.) - die Delegation des Bundesverbandes der Zahnmedizinstudenten in Deutschland

Postgraduierten-Ausbildung sowie das Schreiben und Verteidigen einer Dissertation. Auf Einladung der ERO-FDI (European Regional Organization of the FDI World Dental Federation) nahm FVDZ-Bundesvorstandsmitglied Priv.-Doz. Dr. Thomas Wolf an der Veranstaltung teil. Er hielt einen Vortrag zu „Arbeiten in einem Freien Beruf". Im Anschluss brachte er in einer zweistündigen Podiumsdiskussion, an der auch Vertreter des CED (Council of European Dentists) und der ADEE (Association for Dental Education in Europe) teilnahmen, aktuelle Statements des FVDZ und der ERO ein und sprach über zahlreiche Themen der Standespolitik. Es wurde auch über die derzeitige Situation der jungen Zahnärzte in Europa diskutiert sowie über berufliche Herausforderungen und Probleme, die Niederlassung und das Angestelltendasein sowie mögliche Zukunftsszenarien und wie diese zu beeinflussen sind.

Dr. Ernst-J. Otterbach, Priv.-Doz. Dr. Thomas Wolf 